\title{
Uncovering Factors Influencing Instructors' Decision Process when Considering Implementation of a Course-Based Research Experience
}

Elizabeth A. Genné-Bacon, Jessica Wilks, and Carol Bascom-Slack*

Department of Medical Education, Tufts University School of Medicine, Boston, MA 02111

\begin{abstract}
Course-based undergraduate research experiences (CUREs) are an effective way to expose large numbers of students to authentic research, yet most laboratory courses still use traditional "cookbook" methods. While barriers to using CUREs have been captured postimplementation, little is known about the decision mindset before implementation or what features of CURE design may mitigate perceived barriers. Perception of an innovation (such as a CURE) influences the likelihood of its adoption, and diffusion of innovations theory posits that the decision to adopt is largely influenced by five perceived features of an innovation: relative advantage, compatibility, complexity, observability, and trialability. We conducted interviews with instructors considering using the Prevalence of Antibiotic Resistance in the Environment (PARE) project to assess their perceptions of CUREs and motivations for using PARE. Instructors viewed CUREs as having relative advantages over traditional methods; however, CUREs were also viewed as complex, with instructors citing multiple barriers. Instructors were motivated to use PARE because of its potential scientific impact and compatibility with their courses' structures and resources. Instructors perceived PARE to have few barriers to implementation compared with other CUREs. Designing CUREs that address common instructor barriers and drivers could increase the rate of diffusion of CUREs.
\end{abstract}

\section{INTRODUCTION}

A large body of evidence reveals the importance of authentic research experiences for undergraduate education (Kremer and Bringle, 1990; Alexander et al., 1998; Nagda et al., 1998; Zydney et al., 2002; Lopatto, 2004; Russell and Weaver, 2011; Russell, 2005; Kuh, 2008; Laursen et al., 2010; Cartrette and Melroe-Lehrman, 2012), and national calls to reform science education have recommended the incorporation of more research experiences into undergraduate curricula (President's Council of Advisors on Science and Technology, 2012). Unfortunately, traditional mentored research is often inaccessible to many undergraduate students, particularly those who attend institutions without significant research infrastructure, such as community colleges (e.g., Goedhart and McLaughlin, 2015). This is especially concerning, because community colleges are more likely to enroll students from groups underrepresented in science, such as historically underrepresented minorities and first-generation college students (Aud et al., 2010; Mullin, 2011). Incorporating authentic research into classroom settings (through what are called course-based undergraduate research experiences, or CUREs) has emerged as a powerful way to address the issue of access. CUREs are effective in promoting the positive outcomes associated with traditional research (Howard and Miskowski, 2005; Shaffer et al., 2010; Harrison et al., 2011; Rodenbusch et al., 2016; Cooper et al., 2019), and because CUREs can be incorporated into required course work (including freshman- and sophomore-level courses), they have the potential to engage a greater array of students in authentic research
Rachelle Spell, Monitoring Editor

Submitted Oct 29, 2019; Revised Mar 2, 2020 Accepted Mar 9, 2020

CBE Life Sci Educ June 1, 2020 19:ar13

DOI:10.1187/cbe.19-10-0208

*Address correspondence to: Carol Bascom-Slack (Carol.bascom_slack@tufts.edu).

(c) 2020 E. A. Genné-Bacon et al. CBE-Life Sciences Education ๑ 2020 The American Society for Cell Biology. This article is distributed by The American Society for Cell Biology under license from the author(s). It is available to the public under an Attribution-NoncommercialShare Alike 3.0 Unported Creative Commons License (http://creativecommons.org/licenses/ by-nc-sa/3.0)

"ASCB®" and "The American Society for Cell Biology $\circledR^{\prime \prime}$ are registered trademarks of The American Society for Cell Biology. 
than traditional out-of-class experiences (Bangera and Brownell, 2014).

There has been growth in the number of new CUREs developed (as reviewed in Graham et al., 2013). Despite this, the majority of laboratory class time is still spent in noninquiry activities (i.e., cookbook-style labs; National Research Council, 2012; Beck et al., 2014; National Academies of Sciences Engineering and Medicine, 2015). Published literature suggests that there may be disparity in the types of institutions that use CUREs (Linn et al., 2015). Additionally, a national survey of introductory biology courses found evidence that less class time was devoted to CUREs in community colleges (Spell et al., 2014). There have been many calls to expand development of CUREs aimed at a larger diversity of institutional types and student populations (e.g., Bangera and Brownell, 2014; Carrese, 2015; Community College Undergraduate Research Initiative and Council on Undergraduate Research, 2015). If we want to continue the positive momentum of CUREs, it is time to focus more deeply and systematically on studying factors that influence the adoption and sustained implementation of CUREs (Dolan, 2016). This knowledge can then be translated into best practices for developing and disseminating CUREs.

What makes an instructor decide to begin use of a CURE? Many variables influence one's decision to adopt or reject an educational innovation (Fuller, 1969; Hall, 1979; Blackburn and Lawrence, 1995; Austin, 2011). These may stem from the instructor's personal beliefs or perceived limitations (e.g., personal time, expertise) and/or contextual factors (e.g., perceived attitude of students, departmental norms, access to the necessary recourses; Andrews and Lemons, 2015; Brownell and Tanner, 2012; Ertmer, 1999; Heim and Holt, 2019; Henderson et al., 2011; Henderson and Dancy, 2007; Parker et al., 2015; Shadle et al., 2017; Shortlidge et al., 2016; Walczyk et al., 2007). Some challenges may be unique to or particularly significant for CUREs. For example, time to develop a CURE seems to be an especially large hurdle (Spell et al., 2014; Harris et al., 2015; Shortlidge et al., 2016; Craig, 2017), and the uncertainty of authentic research and need for compatibility with the instructor's own research (Shortlidge et al., 2016) are challenges that are unique to CUREs. These challenges may also differ by institution type. For example, CURE instructors from community colleges and minority-serving institutions commonly report barriers such as lack of research resources/infrastructure, inadequate student preparation, lack of support from colleagues and administration, and financial constraints that research institutions and majority-serving institutions report less frequently (Spell et al., 2014).

Network CUREs are large-scale CUREs developed by one research group and disseminated to different institutions and classrooms throughout the world, examples being the Genomics Education Partnership (Lopatto et al., 2008; Shaffer et al., 2010), SEA-PHAGES (Hatfull et al., 2006; Jordan et al., 2014), the Small World Initiative (Barral et al., 2016), Tiny Earth (Tiny Earth, n.d.), Genome Solver (Mathur et al., 2019), and PARE (Genné-Bacon and Bascom-Slack, 2018). With network CUREs, the overarching research questions and associated laboratory assays have already been established by the CURE developers, eliminating a considerable time burden for instructors implementing the CURE. The popularity and wide reach of network CUREs demonstrates their potential to bring CUREs to more classrooms. Indeed, Lopatto et al. (2014) found that the central support structure of network CUREs helped alleviate the barrier of time to develop and was a factor in sustained use of the CURE. Despite these successes, methods for alleviating other barriers and encouraging the adoption and sustained use of CUREs are still in need of systematic study for CUREs to reach their full potential of widespread use.

In a meta-analysis of literature on instructional practice in science, technology, engineering, and mathematics education, Henderson et al. (2011) conclude that development and dissemination of "best practices" curricular innovations is not an effective approach to elicit change; successful strategies instead include understanding and targeting the individuals enacting the change as well as the institutional context. It has been argued (Dearing, 2009) that rather than designing interventions based primarily on how well a program works internally (i.e., is the intervention effective in a small test group of students?), interventions should instead first be designed around how well a program works externally (i.e., will instructors be able to and want to use this intervention?). Thus, development and dissemination of educational innovations should begin with an understanding of instructors' personal and institutional contexts.

\section{Theoretical Framework}

How innovations are adopted and spread through a population has been a subject of intense study in diverse fields such as marketing, agriculture, sociology, and education.

Rogers developed the diffusion of innovations (DOI) theory to explain how and why innovations are adopted by individuals and, subsequently, spread or do not spread through populations (Rogers, 1962). Diffusion generally refers to the community level, whereas adoption occurs at the level of the individual. DOI is a comprehensive synthesis that considers characteristics of early and late adopters, including the larger cultural and/or institutional contexts of potential adopters. Attention is placed on the motivations and barriers encountered at stages of the adoption process based on the premise that adopters have inherent personality traits that determine their openness to change. Rather than seeking to change the individual, the focus is on creating products that conform to the needs of potential adopters (Rogers, 2004). Rogers articulates the innovation decision process, whereby a potential adopter goes through a decision process weighing the different pros and cons of using the new innovation, ultimately deciding to adopt or reject the innovation.

DOI theory describes five primary stages in deciding whether to adopt an innovation: knowledge gathering, persuasion, decision, implementation, and confirmation (see Figure 1). Characteristics of both the adopter and the innovation are important for determining whether diffusion will be successful. In the knowledge stage, the potential adopter becomes aware of and gathers information about the innovation. In the persuasion stage, the potential adopter develops a favorable or unfavorable view of the innovation. Research synthesized by Rogers (2004) suggests that the persuasion stage is largely influenced by five perceived characteristics of the innovation: relative advantage, compatibility, trialability, observability, and complexity (which include anticipated challenges and barriers). Relative advantage over other methods; compatibility with the adopter's needs, 


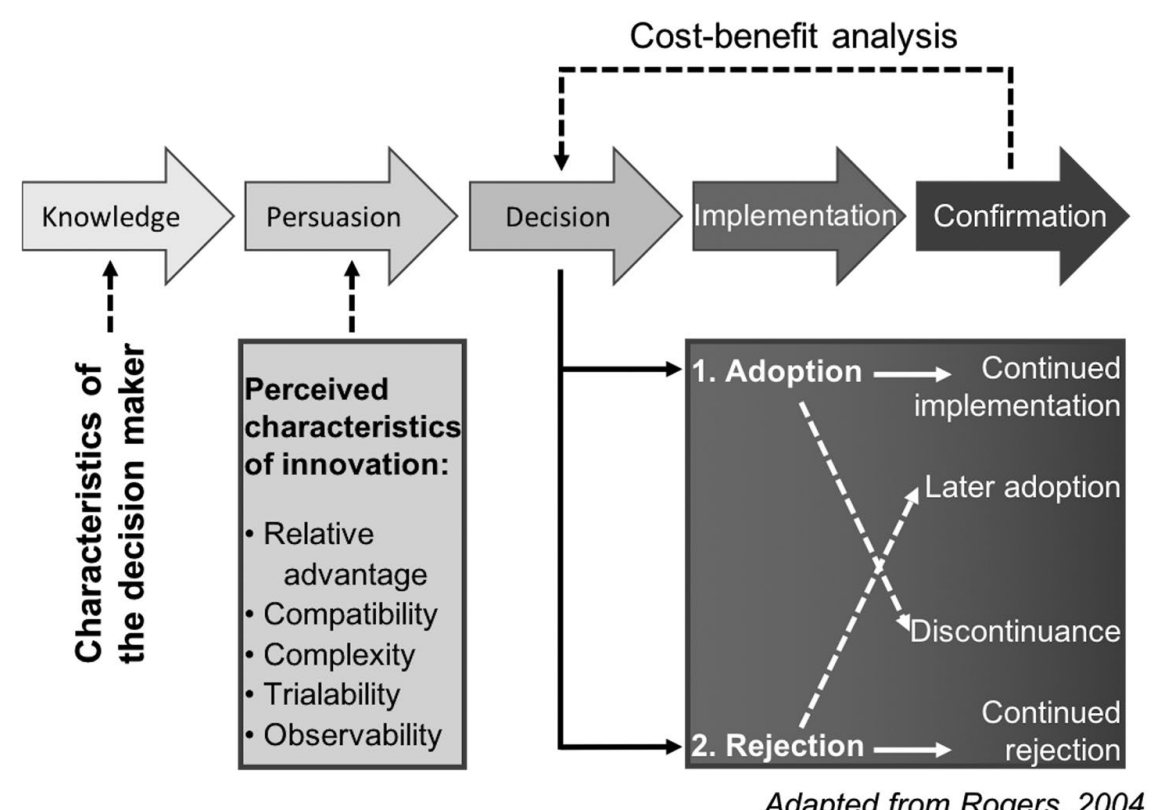

FIGURE 1. The innovation decision process. In DOI theory, the innovation decision-making process describes the five stages an individual goes through when deciding to use (or not use) an innovation: knowledge gathering, persuasion, decision, implementation, and confirmation. This study focuses primarily on the persuasion stage, which is highly influenced by perceived characteristics of the innovation.

beliefs/values, and past experiences; option to observe other people using an innovation (observability); and option to try on a low-risk basis (trialability) —all are positively correlated with adoption. Innovations perceived to be more complex than current methods (i.e., more difficult or with significant barriers to or hurdles for use) are negatively correlated with adoption.

In the decision phase, the potential adopter actively makes a decision whether to adopt the innovation or reject it. A favorable perception of the innovation gained in the persuasion stage is usually necessary for a decision to adopt the innovation. The decision phase is followed by the implementation phase, when the innovation is put to use by the individual for the first time. During use, adopters may modify and continue to gain information about the innovation. In the final confirmation stage, the individual's choice to adopt the innovation is either reinforced and sustained or the innovation is discontinued. The confirmation stage is an ongoing process, during which reinvention and knowledge gathering often continue, and discontinuation is still possible.

Diffusion theory has been applied to study the adoption of several teaching innovations (e.g., Andrews and Lemons, 2015; Henderson and Dancy, 2008; Henderson et al., 2012; Pundak and Rozner, 2008; Warford, 2010; Lund and Stains, 2015; Goodwin et al., 2018). However, diffusion theory has not yet been used to examine the diffusion of CUREs, nor have the perceptions of instructors before the implementation stage been captured. For network CUREs to reach their full dissemination potential, we propose using diffusion theory to understand perceived challenges and motivators as they pertain to different groups of instructors with different levels of CURE experience and within different institutional contexts.

\section{Context of This Study}

The Prevalence of Antibiotic Resistance in the Environment (PARE) project (Genné-Bacon and Bascom-Slack, 2018) was created to address the reported barriers to implementing and sustaining use of CUREs, particularly those faced by institutions without significant research infrastructure, such as small colleges and 2-year institutions (Spell et al., 2014; Harris et al., 2015; Shortlidge et al., 2016). PARE is a network CURE that is short duration and low cost and that uses relatively simple laboratory techniques requiring no specialized equipment. This design renders it embeddable in introductory courses, upper-level courses, and nonmajors' courses at a variety of institution types. In a few class periods, students collect soil samples from diverse geographical locations, analyze them for the presence of antibiotic-resistant organisms, and upload these results into a national database to track trends in the prevalence of environmental antibiotic resistance. Students have the opportunity to formulate hypotheses and analyze data to assess factors correlated with prevalence of antibiotic-resistant organisms in soil samples. PARE is consistent with the general conception of CUREs by introductory biology laboratory instructors, in which scientific discovery or discovery of unknown data is emphasized (Spell et al., 2014). PARE explicitly includes four of five key elements associated with CUREs (Auchincloss et al., 2014; Brownell and Kloser, 2015), especially the elements of broadly relevant work, discovery, and use of scientific practices (Table 1). Additionally, a library of related research modules provides the option to implement a longer, more in-depth classroom research experience based on the needs, resources, and interests of the instructor (Figure 2). With its simple, short-duration core module, plus the add-on modules, PARE attempts to provide a flexible, low-barrier gateway into CURE adoption.

Currently in its sixth year of implementation, PARE has been used in more than 120 institutions across the United States and other nations, $28 \%$ of which are 2 -year institutions. Pilot testing indicates that students make significant knowledge gains (Genné-Bacon and Bascom-Slack, 2018). Informal feedback from instructors indicates high engagement from students and relatively smooth implementation; however, we do not know what aspects of PARE design have led to its appeal, especially among instructors new to CUREs. Studying PARE provides an opportunity not only to elucidate instructors' perceived barriers/challenges for implementing CUREs, but also to gauge the efficacy of the PARE approach in mitigating these challenges.

Understanding the individual decision-making process for adopting or rejecting a CURE is important to inform strategies for diffusion of CUREs. In particular, the preimplementation phases (knowledge gathering, persuasion, and decision) are critical to diffusion of any innovation, because without favorable perception, implementation is not likely to occur. Imagined 
TABLE 1. The PARE project's alignment with key CURE elements

\begin{tabular}{ll}
\hline Key CURE element & \multicolumn{1}{c}{ PARE alignment } \\
\hline Use of scientific practices & $\begin{array}{r}\text { Students form hypotheses about potential sites of antibiotic resistance and use standard microbiology techniques } \\
\text { ("tools of science") to test their selected soil samples and analyze their hypotheses. Students often have to } \\
\text { grapple with the "messiness" of scientific data. Students communicate their findings through the PARE Global } \\
\text { Database, and many instructors provide opportunities for students to share their findings elsewhere (such as at a } \\
\text { school poster session or student research conference). } \\
\text { The outcome of the soil analyses and subsequent follow-up experiments are unknown to both teacher and student. } \\
\text { Each student-provided data point is novel. }\end{array}$ \\
$\begin{array}{l}\text { Discovery } \\
\text { Broadly relevant or } \\
\text { important work }\end{array}$ \\
$\begin{array}{l}\text { Collaboration } \\
\text { Students provide the data for a national research study on antibiotic resistance in the environment. } \\
\text { entire class will work together on analyzing a collection of soil samples. Students also learn about how a } \\
\text { national study such as PARE cannot be done by a single research group; collaboration with students across the } \\
\text { country is necessary. } \\
\text { This is not an explicit requirement, but instructors are encouraged to allow students the opportunity to analyze their } \\
\text { results, troubleshoot experiments, and repeat the procedures when needed. When instructors choose to expand } \\
\text { the research experience with add-on modules, additional experiments will build on earlier ones. }\end{array}$ \\
\hline
\end{tabular}

challenges, incompatibilities, and limitations, whether real or not, can be a barrier to adopting a CURE. To begin to understand the decision-making process for adoption of CUREs, we interviewed instructors from diverse institution types who have recently completed the persuasion phase with respect to PARE, and who have made an active decision to adopt PARE, but have not yet implemented. We examine their views of CUREs and investigate what led them to decide to use PARE. This predominantly qualitative study, based in DOI theory, sets out to answer the following questions:

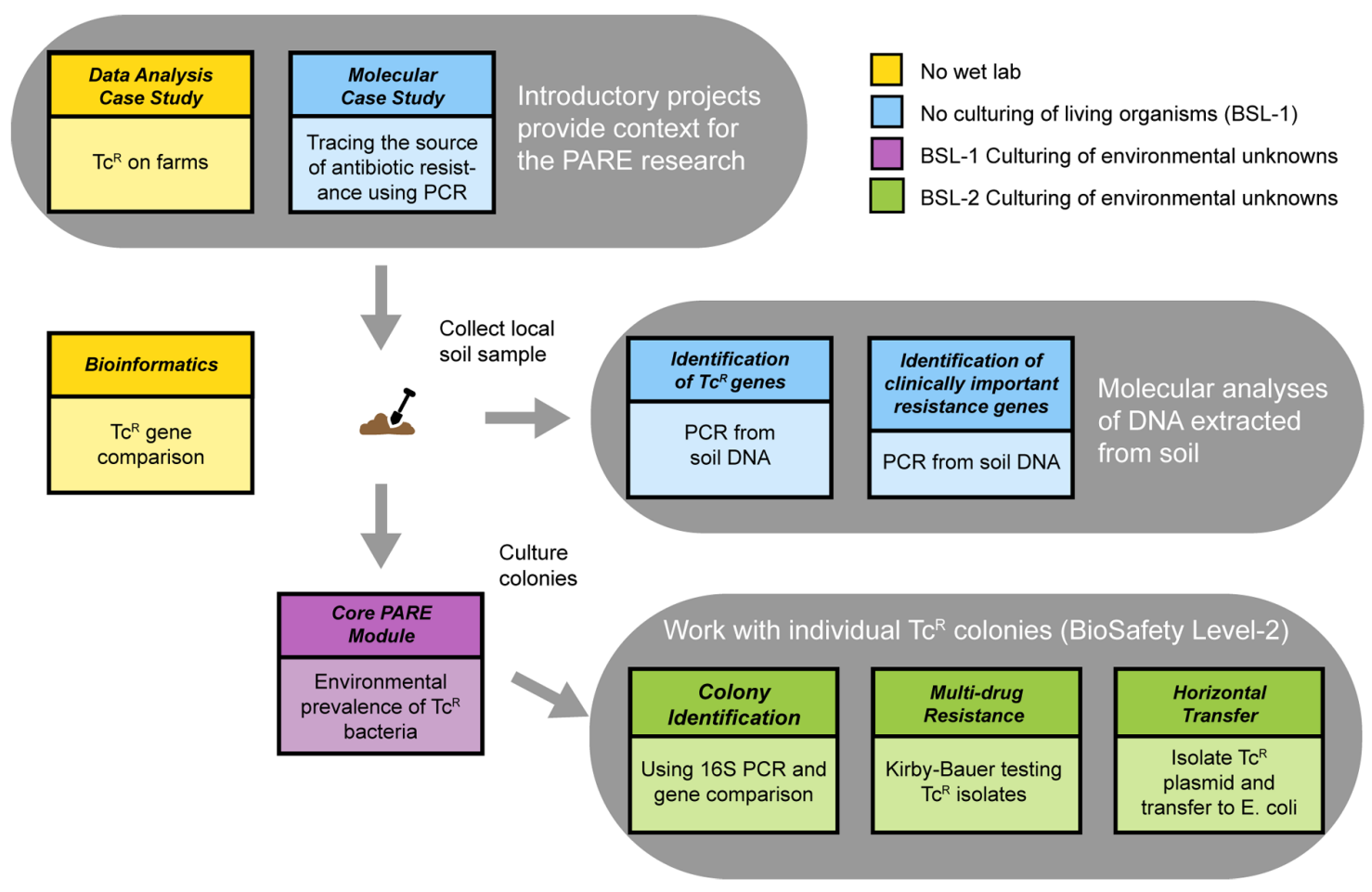

FIGURE 2. The PARE module format allows instructors to pick and choose their students' research experience according to course learning goals, institutional resources, and instructor expertise. All modules are related to studying environmental presence and transmission of antibiotic resistance. In the core PARE module, students isolate bacteria from soil and test for the prevalence of tetracycline resistance $\left(\mathrm{Tc}^{\mathrm{R}}\right)$. Most PARE classes implement the PARE core module first, with additional modules (optionally) added as desired. The order and pairing of these add-on modules can be mixed and matched. Eight expansion modules are currently available, with others in development. Many expansion modules were conceived of and codeveloped by PARE instructors. Add-on modules expand on the research goals of the core PARE module. More details on each module can be found on the PARE website (https://sites.tufts.edu/ctse/pare). Figure created by Madeline Verbica. 
1. How do PARE-interested instructors perceive CUREs?

2. What factors influence instructors' decisions to adopt the PARE project?

3. How does this perception compare with that for other CUREs?

\section{METHODS}

\section{Formative Preimplementation Survey}

For our formative programmatic assessment, in the third year of implementation of the PARE project (2016-2017 academic year), we surveyed new PARE instructors about their perceptions of the project. The anonymous survey was hosted in Qualtrics and sent to instructors through email, before they began implementation of the PARE project. Instructors were asked about challenges they anticipated and motivations for doing the PARE project (a full list of items can be found in Appendix A in the Supplemental Material). The Likert-style survey items were based on anecdotal conversations with instructors about their anticipated challenges, as well as reported barriers from the literature, such as finding time to implement something new (Spell et al., 2014; Shortlidge et al., 2016). Instructors were asked to rate each item on a seven-point scale ranging from "strongly disagree" to "strongly agree." Seventeen undergraduate instructors responded to this survey.

\section{Instructor Interviews}

Recruitment. We investigated a new cohort of instructors (different from those who completed the formative survey) who sought out the PARE program between May and September 2017. All instructors had previously independently inquired about the PARE project, had participated in an informational phone call, and, subsequently, had indicated their intention to implement in the 2017-2018 academic year. Out of the 29 instructors contacted, four were deemed inappropriate for the present study (e.g., were not in charge of the course, had already implemented PARE, etc.) and 20 agreed to be interviewed. Instructors were not compensated or incentivized to participate. Upon being interviewed, one instructor was determined to have already implemented the PARE project (passed the decision stage) and was excluded from analysis for the present study.

Demographic Characteristics of Interviewees. The 19 instructors whose interviews were analyzed represent a diverse range of different institution types: five associate's-dominant colleges (community colleges [CC]), three baccalaureate colleges (including one historically Black college $[\mathrm{HBC}]$ ), six master's-granting, four doctorate-granting (all classified by Carnegie as "very high research activity," also referred to here as "R1"), and one special-focus 4-year college (see Appendix B2 in the Supplemental Material). Because each of the master's-granting institutions is majority or very high undergraduate enrollment (Carnegie classification), we have grouped these institutions together with the baccalaureate and special-focus school as "primarily undergraduate institutions" (PUIs). The majority of instructors (12/19) had no previous experience teaching CUREs, though two of these had worked with CUREs as a teaching assistant during their graduate school or postdoctoral experiences. None of the community college instructors had experience with CUREs, while the CURE experience of PUI and doctorate-granting institutions was mixed (see Table 2).
TABLE 2. CURE experience by institution type

\begin{tabular}{lcc}
\hline Institution type & $\begin{array}{c}\text { Number of } \\
\text { instructors } \\
\text { interviewed }\end{array}$ & $\begin{array}{c}\text { Number of instructors } \\
\text { with prior CURE } \\
\text { experience }\end{array}$ \\
\hline $\begin{array}{l}\text { Community college (CC) } \\
\text { Primarily undergraduate } \\
\text { institution ("PUI") }\end{array}$ & 5 & 0 \\
Doctorate-granting (R1) & 10 & 5 \\
\hline
\end{tabular}

Preimplementation Interviews. We developed semistructured interview questions based on the DOI framework and the goals of our study. Preliminary interview questions were reviewed by education researchers at the Center for Translational Science Education at Tufts University Medical School and subsequently refined. Pilot interviews were then conducted on three experienced PARE instructor volunteers. Interview questions were further refined based on the pilot responses. As with semistructured interviews, the interviewer used a predetermined script of questions but followed up when further clarification or elucidation was deemed necessary (Cohen and Crabtree, 2006). Interview questions focused on the instructor's background and beliefs regarding CUREs; reasons for choosing to try the PARE project; challenges encountered, perceived, or anticipated with CUREs and PARE specifically; and institutional attitudes toward CUREs and other educational innovations. This interview script can be found in Appendix B2 in the Supplemental Material. Interviews were conducted and recorded using WebEx, and audio interview length ranged from 15 to 41 minutes (average: 29 minutes). Interviews were transcribed using the online transcription software Trint and then corrected manually.

Development of the Coding Rubric. We employed thematic analysis to code recorded interview transcripts. We first developed a preliminary coding rubric based on a priori themes from DOI theory as well as emergent themes observed by the interviewer (E.G.B.). One researcher highly familiar with the study (E.G.B.) and one not previously involved with the study (JW) worked together to refine the codes through iterative rounds of independent coding followed by meetings to compare and discuss results. After four rounds of modifications to the coding scheme, 53\% intercoder reliability (typical for this type of complex coding scheme; see Campbell et al., 2013) was attained. Intercoder reliability was measured by taking the number of agreements divided by the total number of codes. The final coding rubric was composed of 15 top-level codes divided into 85 lower-level codes (see Appendix C1 in the Supplemental Material for a list of these upper-level coding categories). Not all coding categories will be discussed in this paper.

In early stages of code development, the DOI persuasion characteristics (relative advantage, compatibility, complexity, trialability, and observability; see Figure 1) were each a unique top-level code, with intermediate levels breaking these categories into codes about PARE or codes about CUREs (CUREs other than PARE as well as the concept of CUREs more generally), and subcodes representing common themes within these persuasion characteristics. In the final version of the coding rubric, this structure remained intact for the categories relative advantage, compatibility, and observability, with subcodes within 
these categories being modified based on emergent themes of the interviews. For the persuasion category complexity, it was found that the original coding structure was too limiting and the themes were too extensive to fit into one upper-level code. Therefore, the category of complexity was broken down into two different upper-level coding groups: barriers and challenges (divided into themes about PARE and themes about other CUREs) and reasons for not previously implementing a CURE. This paper reports a portion of the results of that coding analysis, focused on perceptions of CUREs and PARE specifically. The full, detailed coding rubric for codes reported on in this paper is available in Appendix C2 in the Supplemental Material.

Coding. Coding was carried out by E.A.G.-B. and C.B.S. according to the protocol for in-depth coding of semistructured interview transcripts described in Campbell et al. (2013). This coding method was designed to relieve some of the time and budget burdens of complex, in-depth coding, while retaining a high degree of rigor. Briefly, this coding method involves three distinct stages. The first stage involves refining the application of the coding rubric to reach an acceptable degree of intercoder reliability. A subset of interviews is independently coded by two researchers. After assigning initial codes, the researchers meet to determine the frequency of agreement (how often the two coders assigned the same code-intercoder reliability). In the second stage, disagreements between coders are adjudicated to reach a high degree of intercoder agreement. Any discrepancies are discussed until a consensus is reached (or it is agreed to leave the code unresolved), resulting in a measure of intercoder agreement. Intercoder agreement discussions are important for clarifying how to apply the coding rubric. In the third stage, the coding rubric is fully deployed on the rest of the transcripts. During the intercoder agreement discussions, the researcher most often deferred to is noted, and that researcher then carries out coding of the remaining transcripts.

All interviews were coded using the qualitative data analysis software NVIVO. Because the coding rubric was complex, the rubric was split in half, and each transcript was coded in two passes, once for a first half of the coding rubric and again for the second half. A switch in speaker in the interview transcript was considered a codeable text unit for the purposes of measuring intercoder reliability and agreement. Comparison of 4/19 (21\%) of the transcripts revealed intercoder reliability of $50.9 \%$, a level considered typical for this type of complex analysis (Campbell et al., 2013). Intercoder reliability was measured by the number of agreements in code per text unit divided by the total number of codes for that transcript. Of the codes where there was not agreement, $81 \%$ were cases in which one coder assigned a code where another coder assigned none, as opposed to true disagreements (different codes assigned to the same codeable unit). Thus, in only $9.36 \%$ of assigned codes was there a true disagreement between coders. During intercoder agreement discussions, an intercoder agreement level of $99 \%$ was reached; E.A.G.-B.'s codes were deferred to $67 \%$ of time, C.B.S.'s $28 \%$ of the time, and neither (no agreement or a change to an entirely new code after discussion) $5 \%$ of the time. Thus, the remaining transcripts were coded by E.A.G.-B. alone.

\section{RESULTS}

\section{Formative Assessment of PARE-Interested Instructors Reveals Few Perceived Challenges}

The PARE project was designed to be a flexible, low barrier to entry CURE that could be used in a variety of course contexts. We hypothesized that instructors expressing interest in and intent to implement PARE had chosen it because they perceived PARE as less complex and more compatible than other CUREs. We refer to these instructors as "PARE-interested" to indicate that they had sought knowledge about and intended to implement PARE, but had not yet implemented. For our formative program assessment, we surveyed PARE-interested instructors about their anticipated challenges with using PARE. Survey questions were based on anecdotal conversations with instructors about their anticipated challenges, as well as reported barriers from the literature; see Figure 3). Responses to items with "somewhat disagree," "disagree," or "strongly disagree" reflect that the challenge was not a concern. Responses to items with "somewhat agree," "agree," or "strongly agree" reflect that the challenge was a potential concern. Generally, few of the challenges listed in the survey were of major concern to survey instructors. The items with the highest reported concern were related to program-specific methods ("database upload") and student preparedness ("the students' abilities to execute the project"), both with $23.5 \%$ ( $n=17)$ of instructors agreeing that these were concerns. For two items- "My lack of research experience" and "Dealing with unknown outcomes"-no instructor indicated that these were concerns. "Making classroom time for this project" had the highest proportion of instructors indicating that they "strongly disagreed" that the potential challenge was a concern.

This formative programmatic survey suggested that PARE-interested instructors are not concerned with many previously reported CURE barriers. The PARE project may be perceived differently than other CUREs. Thus, it was decided that a larger, more-in depth qualitative study of PARE-interested instructors was warranted.

\section{Qualitative Results of Interviews with PARE-Interested Instructors}

To better understand the concerns and motivations of PARE-interested instructors, we conducted semistructured interviews with a new cohort of PARE-interested instructors. Instructors were asked about their previous experience and knowledge of CUREs, how they defined CUREs, and their personal beliefs about CUREs, as well as questions about perceptions of PARE specifically (Appendix B in the Supplemental Material). Throughout this study, analysis of perceptions of "CUREs" refers to statements made about CUREs as a concept as well as statements made about specific CUREs (other than PARE). All interviewed instructors intended to implement PARE, but none had actually done so. Thus, we have captured instructors in the "decision" stage of the innovation decision process, allowing us to record instructors' thoughts about their recent progression through the persuasion stage with respect to PARE implementation.

Definition of CUREs. An expert focus group defined CUREs by their incorporation of five key elements: broadly relevant or important work, use of scientific practices, collaboration, iteration, and discovery (Auchincloss et al., 2014). However, it has 


\section{Formative survey results: PARE-interested Instructors' anticipated challenges}

\section{The components of this project that concern me are:}

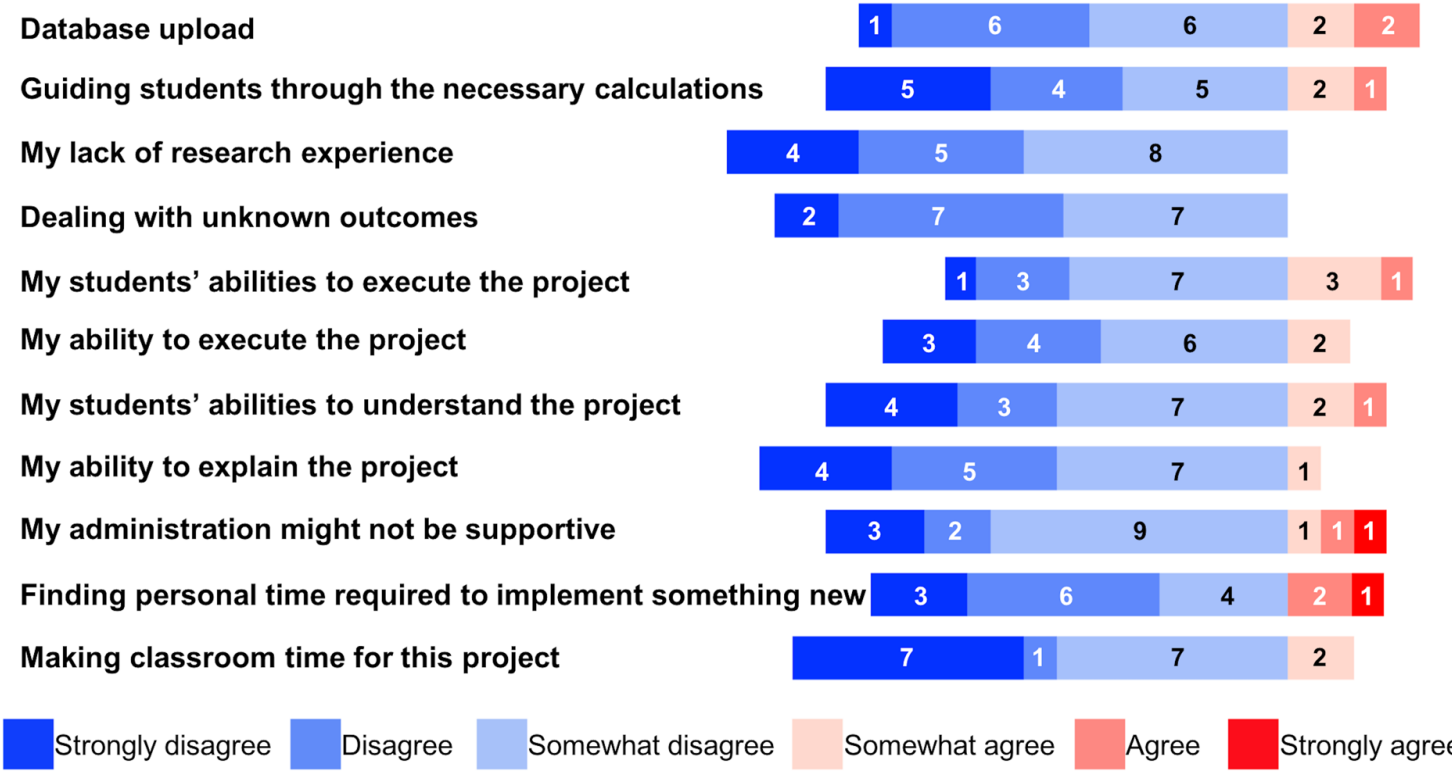

FIGURE 3. Formative assessment results of a survey of new PARE instructors' anticipated challenges with the PARE project, $N=17$. Numbered bars represent the number of instructors selecting that Likert-scale option. Neutral responses (Likert-scale level 4) were omitted from this graphic for ease of viewing.

previously been shown that instructors' perceptions differ with regard to what makes a laboratory activity a CURE (Spell et al., 2014). To investigate how this cohort of PARE-interested instructors define CUREs, we asked instructors what they believe the key elements of a CURE are, and we coded answers in accordance with the categories articulated by Auchincloss et al. (2014) and further described by Brownell and Kloser (2015). Though some recent literature has argued that the CURE element categories of broad relevance and discovery should be combined, we chose to code these elements separately (Brownell and Kloser, 2015; Corwin et al., 2015; Cooper et al., 2017, 2019). A significant number of instructors touched upon an additional element-a student's sense of ownership over the project-which is not emphasized in Auchincloss et al. (2014), Spell et al. (2014), or Brownell and Kloser (2015), though it has been discussed as an important aspect of CUREs and other inquiry-based science education methods (Hanauer et al., 2012; Hanauer and Dolan, 2014; Corwin et al., 2018; Cooper et al., 2019). See Table 3 for a complete summary and example quotes.

No instructors mentioned all previously articulated aspects of CUREs when asked to give their personal definitions of what makes a lab experience a CURE, and there was no substantial difference between instructors with CURE experience and those without. The most commonly stated elements were discovery (11/19 instructors mentioning), use of scientific practices (10/19), "ownership" (9/19), and broadly relevant work (8/19). See Appendix D in the Supplemental Material for a summary of coded CURE elements for each interviewed instructor.
Perceived Relative Advantage of CUREs. In the DOI framework, perceived relative advantage of an innovation is a key attribute correlated with likelihood of adoption (Rogers, 2004). If the decision maker does not perceive the innovation as having advantages over other teaching options, he or she is unlikely to adopt the innovation. To understand why this cohort of instructors intended to implement PARE, we first examined whether they generally viewed CUREs as having relative advantage over other teaching methods. We probed instructors for their thoughts on the relative advantage of CUREs, using questions such as "How do you feel about course-based research compared with traditional labs or other teaching methods?" In addition, instructors often spontaneously offered their opinions of CUREs throughout their interviews.

All interviewed instructors spoke of the relative advantage of CUREs. During the coding process, several subthemes of relative advantage emerged from the interviews (Table 4). These were:

Increased Student Learning. This relative advantage code was used for statements about how CUREs develop students' laboratory skills and ability to understand content and/or enhance their understanding of the scientific process. For example, this quote describes how the instructor believes CUREs go beyond teaching content to enhance students' skills and understanding of the scientific process:

"I think CUREs are a better way to... teach a whole new set of skills: developing hypotheses, doing an experiment. ... It's more skills based, I guess, and less content based, which I 
TABLE 3. How PARE-interested instructors define CUREs

\begin{tabular}{|c|c|c|}
\hline $\begin{array}{l}\text { CURE element } \\
\text { category }\end{array}$ & $\begin{array}{l}\text { Number of instructors } \\
\text { mentioning }\end{array}$ & Example quote \\
\hline Discovery & 11 & $\begin{array}{l}\text { "I think what would make a lesson a CURE is that there's not an outcome that's set. We're not } \\
\text { working towards a particular outcome that's in the lab manual. The outcome is actually } \\
\text { unknown. So, we have ... some ideas of what we might get but we actually don't know } \\
\text { what the results will be." }\end{array}$ \\
\hline Scientific practices & 10 & $\begin{array}{l}\text { "They think about the question, they think about the comparisons that they want to make. } \\
\text { They think about hypotheses, they think about literature ... what has been shown already, } \\
\text { what are people doing, what are the techniques that we can adapt to answer the question } \\
\text { that we are interested in?" }\end{array}$ \\
\hline $\begin{array}{r}\text { Broadly relevant or } \\
\text { important work }\end{array}$ & 9 & $\begin{array}{l}\text { "The fact that it's ... authentic research. That it's actually being used in a wider study and that } \\
\text { it's not simply doing it for its own sake ... being part of a broader ... research study." }\end{array}$ \\
\hline "Ownership" & 9 & $\begin{array}{l}\text { "So, students... They can feel ... ownership of the project. 'This is my project. It's not just } \\
\text { because we have to do it and just leave within an hour or two hours or whatever, no it is } \\
\text { our project ... We have to be really responsible, accountable for the things that we are } \\
\text { producing.". }\end{array}$ \\
\hline Collaboration & 3 & $\begin{array}{l}\text { "The idea of collaboration across many sites and requiring standard protocols, I think gives } \\
\text { students a real flavor of what authentic scientific research is like." }\end{array}$ \\
\hline Iteration & 3 & $\begin{array}{l}\text { "They're learning the process of science, and just like in science if things aren't working ... They } \\
\text { may have to redo something." }\end{array}$ \\
\hline
\end{tabular}

think is something that is important for students to actually get exposure to. Here's what it's actually like to be a scientist; not here's what it's like to actually know the facts that a scientist needs to know."

As another example, a different instructor discusses how the critical-thinking and scientific process skills that they believe are taught through CUREs have more value for students' career development:

"In all reality most places if you got a job ... a lot of the specific skills that they're going to want you to learn, they would probably teach you. But it's much more valuable in my mind for a student to engage in science-think about the scientific process, see what it's actually like when you do science. It's not always necessarily the clear-cut scientific method that we teach them about. You know, things don't go as planned. So, I think it's really, really important that students are engaging in those types of activities more."

Increased student learning was the most commonly coded relative advantage theme, with 15 out of 19 instructors (3 CC, 10 PUI, 2 R1) mentioning it at least once in their interviews.

Increased Student Engagement. This relative advantage code was used for statements about how students felt about or engaged with CUREs compared with other laboratory teaching methods. These types of statements often discuss students feel- ing excited or invested in their projects or enjoying the class more when doing CUREs. For example:

"It's way better than a cookbook lab. They [the students] are into it, they are invested, they think about it, they ask you questions, they send e-mails [about] stuff that they read that's related, and they're just understanding the process more."

Increased student engagement was the second most commonly coded relative advantage theme, with 13 out of 19 instructors (3 CC, 7 PUI, 3 R1) touching on it at least once.

Dissatisfaction with Old Methods. This relative advantage code was used when instructors discussed their preference for CUREs in terms of their dislike of current or old methods. This dissatisfaction was often directed at traditional lab-manual style lab experiences, with emphasis on how those lab experiences do not teach "real science," or how students are not invested in traditional lab courses. For example:

"[We want to change the curriculum to CUREs] to meet the learning goals that we were trying to meet, because cookbook labs don't really meet your goals of students behaving like scientists in any stretch of imagination."

Dissatisfaction with old methods tied with increased student engagement as the second most commonly coded relative

TABLE 4. Perceived relative advantage

\begin{tabular}{llcc}
\hline Perception category & \multicolumn{1}{c}{ Specific theme } & $\begin{array}{c}\text { No. of instructors mentioning } \\
\text { for CUREs (out of 19) }\end{array}$ & $\begin{array}{c}\text { No. of instructors mentioning } \\
\text { for PARE (out of 19) }\end{array}$ \\
\hline Relative advantage & Impact & 5 & 15 \\
& Increased student engagement & 13 & 11 \\
& Dissatisfaction with old methods & 12 & 8 \\
& Increased student learning & 15 & 6 \\
& Career incentive & 9 & 3 \\
\hline
\end{tabular}


advantage theme, with 13 out of 19 instructors (2 CC, 9 PUI, 2 R1) expressing this dissatisfaction with old methods as an incentive for using CUREs at least once.

Career Incentive. This code refers to when the instructor expresses that using CUREs might provide advantages to advancing her or his career. For example:

"My chair will be happier with me if I'm doing CUREs rather than traditional labs. So, I just might get higher raises than if I were trying to do traditional labs."

Nine out of 19 instructors (1 CC, 5 PUI, 3 R1) mentioned career incentive as a relative advantage of CUREs.

Impact. This code refers to the potential for CURE research goals to have a broader impact on the world and/or scientific community. For example:

"We're not just doing this for a lab exercise, we're actually doing something that is going to help or is going to be used by the scientific community."

Impact was cited as a relative advantage of CUREs by six out of 19 instructors (1 CC, 4 PUI, 1 R1).

Collectively, these five relative advantage themes were cited a total of 68 times across all 19 interviews.

Perceived Relative Advantage of PARE. To understand motivations for implementing PARE, instructors were prompted with interview questions such as "What originally caught your interest in the PARE program?" and "Why are you planning to implement PARE and not another CURE?" Nearly all (18/19) interviewed instructors spoke of relative advantages specific to PARE not only when asked about PARE but also spontaneously in answers to questions about CUREs in general. As with CUREs, we coded for five major relative advantage subthemes (see Table 4). During coding, we carefully distinguished statements that referred specifically to the PARE project from statements about other CURES or CUREs more broadly. As with our analysis of interviewees' perceptions of CUREs, increased student engagement and dissatisfaction with old methods were major themes. However, unlike our analysis of CUREs, impact emerged as a major relative advantage theme specific to the PARE project, while increased student learning and career incentive seemed to be less important specifically for PARE. We discuss these in the following sections.

Broader Impact. This relative advantage code was used when instructors made statements relating to the broader impact and scientific goals of the PARE project. Broader impact is one of the proposed key elements of a CURE (Auchincloss et al., 2014). Many instructors expressed enthusiasm about searching for antibiotic-resistant organisms in the soil, especially when it came to tying research to their own communities. For example:

"So as a group we kind of wanted something that had a more direct impact on our local community.... We also wanted to sort of tie something towards the problems of industrial contamination and pollution that we have here in [city]."
"One of the things that you guys I think were interested in was this idea of connections to rural areas, connections to farms.... We're in a fairly rural area where there's lots and lots and lots of farmland-both agricultural and commercial animal farms in the area where we live. And so, I thought that might also be really interesting that we could provide an extra data point that might help to analyze those things."

Instructors also seemed motivated by the idea that their students' data would contribute to a larger research effort. For example:

\begin{abstract}
"The idea that this might end up being a peer-reviewed publication at some point is appealing to me.... When I introduce it, it's going to be 'this is a real project. This is not some rinky-dink lab exercise. This is the real thing with real research and so it's important that you guys do your best."'
\end{abstract}

Impact was the most commonly coded PARE-related relative advantage theme, with 15 out of 19 instructors (4 CC, 8 PUI, 3 $\mathrm{R} 1)$ touching on this theme at least once in their interview

Increased Student Engagement. This relative advantage theme was coded when instructors talked about how they believed the PARE project would be engaging or exciting to their students. As with CUREs in general, many instructors felt that participating in course-based research would make their students more invested in their course work. This code was only used when instructors made clear that they were specifically talking about the PARE project's potential (as opposed to CUREs in general) to increase student engagement. For example:

"I think the question of antibiotic resistance is extremely attractive to students. It's something that they understand and can relate to. You know they've heard about it in the news or maybe someone that they know has had an infection that's been resistant to different antibiotics or things like that. So, it's something that a lot of them really kind of latch on to and get really excited about."

Increased student engagement was the second most commonly cited relative advantage theme specific to PARE, with 11 out of 19 instructors (3 CC, 6 PUI, 2 R1) mentioning it at least once.

Dissatisfaction with Old Methods. This relative advantage theme was used when instructors discussed their specific preference for PARE in terms of their dislike of their current or older teaching methods. As with CUREs in general, this dissatisfaction was often directed at cookbook-style labs. Instructors also often sometimes discussed their dissatisfaction with previous inquiry-based or CURE-based lab methods. For example:

\footnotetext{
"So, the past projects that we've done were problematic because they just weren't able to make a connection between discovering something in this model organism and applying it to why they should care."
}

Eight out of 19 instructors (3 CC, 3 PUI, 2 R1) mentioned dissatisfaction with old methods specifically in the context of discussing PARE. 
Other Relative Advantage Themes. Other themes occasionally mentioned specifically in the context of the PARE project were increased student learning (6/19 instructors) and career incentive (3/19 instructors).

Collectively, these five relative advantage codes were cited in the context of the PARE project 59 times across 18 interviews.

Perceived Compatibility. DOI theory defines compatibility as the degree to which an innovation is perceived as consistent with the existing values, past experiences, and needs of potential adopters and identifies it as one of the key aspects of an innovation that contributes to its likelihood of adoption. Throughout the interviews, instructors offered explanations for why they were choosing or rejecting certain CUREs (including PARE). Our iterative code-development process identified four major compatibility-related themes: compatibility with values and beliefs, compatibility with past experiences, compatibility with course structure or content needs, and compatibility with costs or resources.

Compatibility of CURES. In our analysis of statements about CUREs other than PARE, three of the four major compatibility themes (values and beliefs, past experiences, course structure/ content) emerged. Most (14/19), though not all, instructors touched upon some theme related to CURE compatibility, as discussed in the following sections (see Table 5).

Compatibility with Past Experiences. DOI theory recognizes that previously held ideas form the basis through which new innovations are judged. In our coding rubric, this theme resulted from combining two separate coding categories: one for general statements about compatibility with past experiences and one specific for answers to the question "How has your professional training influenced your decision to implement PARE or CUREs in general?" Many instructors discuss how their own experiences with research as a student, trainee, or professional have influenced the decision to use CUREs in their classes.

For example:

"So, I have my Ph.D.... I've been in lab research and I think that it's a valuable experience for any sort of undergraduate student to have just to see what that's like and understand... even if they're not going to go into research as their career."

Compatibility with past experiences was the most commonly coded compatibility theme for CUREs, with 12 out of 19 (4 CC, 7 PUI, and $1 \mathrm{R} 1$ ) instructors touching on this theme at least once.

Compatibility with Values and Beliefs. In DOI theory, this is a broad category of compatibility, encompassing diverse elements such as spiritual beliefs, cultural practices, personal feelings, and values. In our analysis, we coded statements as compatibility with values and beliefs when instructors made statements about their personal feelings or motivators regarding the use of CUREs. For example:

"[It's] sort of my pet project right now because, I mean, I really do believe that this experience of authentic research in the laboratory is really important for students."

"One of the goals that we put into that grant was to increase success in general biology by promoting inclusivity. And one of the ways in which we felt that we could do that was moving to a more undergraduate research-based experience in the labs."

Compatibility with values and beliefs was the second most commonly coded compatibility theme, with 11 out of 19 (2CC, 6 PUI, 3 R1) instructors expressing this compatibility at least once.

Compatibility with Course Structure or Content. While this theme was primarily observed in instructors' perceptions of the PARE project (see below), a small number of instructors (4/19) (Table 5) talked about the compatibility of specific CUREs other than PARE. For example:

\begin{abstract}
"It's one day sampling, extracting the DNA and then they have the advantage of their way of doing is just sending it off for the sequencing.... So, my students don't have to succeed at what are honestly fairly difficult skills for them."
\end{abstract}

Collectively, these three compatibility themes for CUREs in general were cited a total of 26 times across 14 of the 19 interviews.

Compatibility of PARE. Similar to our analysis of CUREs, compatibility with past experiences was a major theme for PARE. In contrast to our analysis of perceived general CURE compatibility, compatibility with cost and resources and with course structure or content were major themes for PARE, while compatibility with values and beliefs was not as prominent. All (19/19) instructors discussed ways in which PARE was compatible for them (see Table 5). We discuss these in the following sections.

Compatibility with Course Structure or Content. This emergent compatibility theme was by far the most common for PARE, with 16 out of 19 instructors (3CC, 9 PUI, 4 R1) touching on this. Instructors often discussed how they chose PARE because the content it covers is very similar to what was already covered in their classes, so it was easy to "slip right in." For example:

TABLE 5. Perceived compatibility

\begin{tabular}{llcc}
\hline Perception category & \multicolumn{1}{c}{ Specific theme } & $\begin{array}{c}\text { No. of instructors mentioning } \\
\text { for CUREs (out of 19) }\end{array}$ & $\begin{array}{c}\text { No. of instructors mentioning } \\
\text { for PARE (out of 19) }\end{array}$ \\
\hline Compatibility & Compatibility with course structure or content & 4 & 16 \\
& Compatibility with costs and resources & 1 & 11 \\
& Compatibility with past experiences & 12 & 10 \\
& Compatibility with values and beliefs & 11 & 2 \\
\hline
\end{tabular}


"They're already techniques that the students have already covered at this point in lab. So, they're familiar with how to do serial dilutions, they're familiar with how to do plating and calculating CFUs per ml.... So, I think it just matches up a little nicer with the content of our course and our capabilities."

"I'm always kind of on the lookout for things to refresh my lab, and ... the elements of this project seem like one that I could instantly kind of just drop into my lab, right? It's got elements of dilution and plating. It's got selection and screening elements to it. Those are things that we teach in my lab."

Instructors also frequently discussed the short duration or module format of PARE as relatively easy to fit into their courses without having to make significant changes to existing structure.

\begin{abstract}
"So, part of it too is that this semester having PARE as an option and have it being a little bit... just, you know, a little bit more bite sized. It's something that can be done in, you know, two weeks as opposed to the whole entire semester."

"I really like the modular aspect so I can pick and choose and emphasize different things with each module. And also, you know, I find that certain students are interested in one project and not another. So, I do like to give a little bit of variety so, for that student who's not interested in one of our CURE modules it's not the whole semester for them; that hopefully a different module will pique their interest."
\end{abstract}

Compatibility with Costs and Resources. Compatibility with the instructors' course funding and/or available equipment or supplies was another common theme for PARE, with 11 out of 19 instructors (3 CC, 8 PUI, 0 R1) discussing this issue at least once. As seen in our analysis of the challenges instructors often encounter with using CUREs, access to equipment is often a common concern. For example:

“So, for me being in a small school where we don't have as much... I mean, we don't have DNA sequencing equipment, we don't have some of those things the larger school does. I mean like I said the PARE project... the materials that go into it, the techniques that go into it are a lot easier for us to do."

Even more frequently cited than equipment access, was how the PARE project was compatible with the instructors' course budget. For example:

"One thing that also attracted me [to PARE] is it's low cost, because my budget is really low and I come from a microbiology background, and it's always like anything I wanted to do research-wise, I just couldn't afford it."

"It's so much less expensive than just even buying other consumables that we use in the lab like plasmids and competent cells and it's just so much cheaper and just a fantastic very inexpensive way of doing a yearlong project for these classes. So, I think it's great."

Compatibility with Past Experiences. Just as instructors discussed past research experiences as influencing their percep- tions of CUREs, they also discussed this in the context of the PARE project. Ten out of 19 instructors (3CC, 5 PUI, 2 R1) touched upon this theme at least once, often mentioning their personal microbiology backgrounds as motivation for using PARE. For example:

"I was interested in trying to figure out some sort of coursebased undergraduate research that students could do in our intro class. I'm a microbiologist and so I've done some work with undergraduates in isolating soil bacteria and looking at antibiotic resistance. And so, because it's aligned with my research and some of the stuff that I've done in the past, when I saw you guys were doing that, it seemed to fit pretty well with another project that I started at a different institution."

One other compatibility theme, compatibility with values and beliefs, was not commonly discussed in relation to the PARE project specifically. Together, the three prominent compatibility themes were coded 68 times across all 19 interviews.

Perceived Complexity. In DOI theory, the perceived complexity of the innovation is negatively correlated with adoption. In other words, if the potential adopter thinks that the innovation is more difficult to use and understand than other options, the rate of adoption is likely to be low. For our analysis, we defined complexity in terms of challenges and barriers (whether perceived or experienced) to using PARE or other CUREs.

Complexity of CUREs. We investigated perceived complexity of CUREs among the interviewees in a number of ways. For instructors who had no previous experience with CUREs (12/19 instructors), we asked, "What has prevented you from implementing a CURE before?" For instructors with previous CURE experience, we asked, "Are you still using this CURE? Why or why not?" and "What challenges have you encountered with this CURE?" Beyond the confines of these questions, instructors also spontaneously mentioned challenges or degrees of complexity associated with CUREs-either other CUREs they had implemented or heard of or with respect to the concept of CUREs more broadly. Some responses to the question "What has prevented you from implementing a CURE before?" did not reflect a complexity theme (e.g., lack of awareness) and so were excluded from this analysis.

All 19 instructors mentioned some type of perceived or experienced challenge with implementing CUREs (see Table 6). The major complexity/challenge themes that emerged are discussed below.

Instructor Bandwidth. This theme deals with responses that discuss lack of personal time, energy, or mental space ("bandwidth") to begin or manage the implementation of a CURE. For example:

"That was one of the biggest limitations... just not having, you know, the bandwidth to myself to kind of go through so many projects in the class"

"Basically, the amount of work required in prepping an authentic research experience from scratch-You know, in terms of 
TABLE 6. Perceived complexity

\begin{tabular}{llcc}
\hline Perception category & \multicolumn{1}{c}{ Specific theme } & $\begin{array}{c}\text { No. of instructors mentioning } \\
\text { for CUREs (out of 19) }\end{array}$ & $\begin{array}{c}\text { No. of instructors mentioning } \\
\text { for PARE (out of 19) }\end{array}$ \\
\hline Complexity & Student challenges & 8 & 8 \\
& Available resources & 12 & 6 \\
& Specific technical issues & 1 & 3 \\
& Instructor bandwidth & 12 & 2 \\
& Time in semester & 11 & 2 \\
& Managing teaching assistants & 1 & 1 \\
& Institutional conflicts & 5 & $\mathrm{n} / \mathrm{a}$ \\
& Scaling for large classes & 4 & 0 \\
\hline
\end{tabular}

establishing the protocol, writing up the materials—was, you know, somewhat prohibitive."

Five PARE-interested instructors (1 CC, 2 PUI, 2 R1) indicated that lack of bandwidth had prevented them from implementing CUREs before. An additional seven instructors (1 CC, 5 PUI, 1 R1) mentioned bandwidth as a challenge to implementing CUREs, for a total of 12 instructors touching on this complexity theme.

Available Resources. This theme deals with responses that discuss lack of institutional, departmental, or classroom resources (such as equipment access or funding limitations). For example:

\begin{abstract}
"We're at a very small school and we don't have, you know, a lot of the equipment that a larger school might have. We don't have DNA sequencing capability and, you know, some of the other things that some of the more common large projects require."

"We have an extremely limited lab budget at this college of only $\$ 15,000$ for all the instructors for all the labs for the entire academic year. And so, part of what I've been trying to do is find things that cost very, very little money that we can fit into regular instruction. So, because of our incredibly tiny lab budget a lot of the other CUREs I've seen have been just off the charts expensive, something we can never afford to do."
\end{abstract}

Five instructors (3 CC, 2 PUI, including 1 HBC) mentioned limited funding or access to equipment as reasons they had not implemented a CURE before. An additional seven instructors (1 CC, 4 PUI, 2 R1) mentioned resource limitations as being significant challenges to using CUREs, for a total of 12 instructors touching on this barrier. Instructor bandwidth and available resources tied for the most commonly coded complexity themes.

Time in the Semester. Another common challenge theme that emerged from these interviews was the lack of time in the semester to fit a CURE. Time in the semester to implement a CURE should not be confused with a lack of instructor personal time (instructor bandwidth) to develop or plan the use of a CURE. Like other challenge codes, this theme draws from the answers to "What has prevented you from implementing a CURE before?" as well as general statements about challenges. For example:
"So, there's nine discussion sections throughout the semester and they meet for one hour each time. So, basically, I've only dedicated, I think, three to doing any sort of experiment things. So, there's a really big limit there."

In addition, we created a subset of the time in the semester complexity theme, in which we tracked how many instructors specifically mentioned transforming their whole class or a whole semester of activities. For example, one instructor discussed making the choice not to use a semester-long network CURE:

"I would have an uphill battle getting a new class approved to do it, right? Because I would see it as a new class. There are some standards that this class is expected to adhere to. There are certain things that we are expected to teach. [....] So trashing the whole class and saying 'I'm going to do a whole semester of [semester-long network CURE]' is just not plausible because I've got other things that we have to maintain for the class."

Similarly, this instructor says that the semester-long length of many network CUREs has prevented her from previously using CUREs:

"I've looked at others in the past, but I've never tried to implement them largely because I found a lot of them to be like a whole semester long. So, I just wasn't looking to commit to one CURE for a whole semester. And I feel like you need a balance. Different CUREs emphasize different things."

Six instructors (2 CC, 2 PUI, 2 R1) mentioned having to transform a whole class as a challenge to doing CUREs. An additional five instructors (2CC, 2 PUI, 1 R1) mentioned not having enough time in the semester as a challenge to doing CUREs, for a total of 11 instructors touching on this theme.

Student Challenges. Anticipated or experienced student-related challenges was another common complexity theme. The most common concern (mentioned by seven instructors) was a lack of student competence or readiness to successfully participate in the CURE. For example:

"That [CURE] was challenging especially considering that they were freshmen and they really just didn't have a lot of other experiences to draw from. [...] I think just because of how big [the CURE] is and the fact that they had zero experience with 
it before was really challenging because every step of this was new for them."

In addition, student reluctance to fully engage with the CURE was cited as a challenge by four instructors. For example:

"Well I've been working to move it towards CUREs [...] But the students weren't very excited about some of them because they worked with, say, a bean beetle as their model organism. So, they really weren't motivated by the research questions there."

A total of eight instructors (1 CC, 4 PUI, 3 R1) mentioned some form of difficulty with working with students as a challenge for using CUREs.

Other Challenges. Other less commonly coded challenge themes included conflicts within the instructor's institution (five mentions), trouble scaling for large class sizes (four mentions), technical issues with specific CURE protocols (one mention), and difficulties managing teaching assistants (one mention). Other noncomplexity reasons for not previously using a CURE include lack of awareness (five mentions) and just started teaching (three mentions).

Complexity of PARE. To investigate the perceived complexity of PARE, instructors were asked "What barriers or challenges have you encountered, or anticipate encountering when implementing PARE?" (no interviewee had yet implemented PARE, but some may already have encountered challenges such as acquiring needed materials). If instructors were not forthcoming with any challenges, they were prompted further by asking how their students would handle the project, whether they were having any trouble with obtaining materials or funding for the project, or whether they were encountering any other logistical difficulties preparing to use PARE. Results followed a very different pattern than that of the perceived challenges of CUREs (see Table 6), as discussed in the following sections.

Student Challenges. Anticipated student-related challenges were the most commonly perceived challenge associated with PARE, with eight out of 19 instructors (2 CC, 6 PUI, 0 R1) mentioning this complexity theme. As with our reporting of CURE complexity, student preparation/competency and student reluctance to engage with the project were common subthemes anticipated for the PARE project. Students' ability to properly execute serial dilutions of their soil samples was a very common example of student competency concerns. For example:

"I really like the idea of running practice serial dilutions ahead of time.... My biggest concern is the first time they will screw up. They will misread. My current group is really, really prone to thinking they know what's going on, and then halfway through it going, 'wait a minute- I should have read the directions!' ... So, I mean there's still the distinct possibility that they're going to mess up."

Available Resources. Similar to the themes that arose in instructors' perceptions of other CUREs, available resources repre- sented a prominent PARE-related perceived challenge, with six out of 19 instructors (3 CC, 2 PUI, 1 R1) mentioning this complexity theme. A common theme of PARE-related resource concerns was managing the number of agar plates required to complete the project. For example:

\begin{abstract}
"We're going to pour something like twelve hundred MacConkey plates. More. At 360 students paired up, that's a lot of MacConkey plates, right... And so right now where I'm getting resistance, is actually from our media people.
\end{abstract}

The upfront costs to buy some of the supplies for the project were also reported as a challenge by some instructors. For example:

\begin{abstract}
"The only very small, very surmountable barrier was cost of individual reagents. Because, not that they were outside our budget, but my class was fairly small so justifying some of the antibiotics, antimicrobials for a small class."
\end{abstract}

However, no instructor reported cost as a challenge that might prevent them from doing the project altogether.

Other Challenges. Student challenges and available resources were the only commonly perceived challenges mentioned for the PARE project. In addition, three instructors discussed specific technical issues with the PARE lab protocol for which they needed guidance, two touched on lack of bandwidth, two had concerns about time in the semester or class period, and one instructor mentioned issues managing teaching assistants working on PARE (the same instructor who had this challenge with other CUREs).

Perceived Trialability and Observability of PARE and Other CUREs. In diffusion theory, perceived trialability is the degree to which the innovation can be tried out on a limited basis, with little cost or risk. Observability is the degree to which one can see the results of the innovation (e.g., as used by others). Both are positively correlated with adoption. We investigated how instructors perceived PARE and other CUREs with respect to these two characteristics. Unlike the other characteristics we have discussed thus far (relative advantage, compatibility, and complexity), trialability and observability did not emerge as major themes.

\section{DISCUSSION}

This study uses DOI theory to frame examination of why instructors from diverse institutional types are persuaded (or not) to attempt implementation of CUREs. We use PARE as a model system in which to study motivation for using CUREs and barriers to CURE implementation. PARE was designed with the goal of attracting instructors who might otherwise not use CUREs, so we sought to understand what factors influence instructors' decisions to adopt the PARE project. We also asked how this perception compares with perception of other CUREs, as well as these instructors' conceptions of CUREs in general. Our hope is that our results can be used to inform future CURE design and dissemination.

\section{Definitions of CUREs}

To place PARE-interested instructors' perceptions of CUREs in context, it is important to understand how they define CUREs. 
The most commonly cited CURE elements among our group of interviewed instructors (discovery, broadly relevant work, and use of scientific practices), largely align with the elements emphasized in the PARE project. This could indicate that PARE is more attractive to instructors who value discovery and broadly relevant research than to those who value features less emphasized by PARE, such as iteration. Interestingly, nearly all interviewed instructors mentioned either discovery or broad relevance (see Appendix D in the Supplemental Material) in their definitions, which may support combining these categories (Brownell and Kloser, 2015; Corwin et al., 2015; Cooper et al., 2017, 2019).

In a national survey of instructors who teach CUREs to firstyear students, Spell et al. (2014) found two main conceptions of CUREs: one that emphasizes development of scientific process skills and one that emphasizes answering authentic research questions, with little overlap between these. Our method of study is considerably different from that of Spell and colleagues, and we do not find a clear pattern that reliably divides these two conceptions. Instructors often discussed developing scientific process skills along with answering broadly relevant questions (see Appendix D in the Supplemental Material). Our sample is not large enough to extrapolate, but it is possible that information about the nature of CUREs has diffused more broadly in the years since Spell et al.'s (2014) study, such that perceptions have changed. In addition, the participants in the present study may have a greater knowledge base about CURES because they have already engaged in knowledge-seeking about PARE (Figure 1). Moreover, Spell and colleagues recognized that different CUREs emphasize different components of the research experience, so the undergraduate course of study should consider the cumulative set of CURE components a student may encounter. Recognition that individual CUREs each provide different components of the research experience is supported by our interview data. A short-duration and/or module-style CURE could provide flexibility for students to experience multiple CUREs in a single semester, each emphasizing different aspects of the scientific process.

\section{Consensus That CUREs Have Potential for Increased Student Learning Relative to Traditional Methods of Laboratory Instruction}

We originally hypothesized that, because the instructors in this study had completed the knowledge-gathering stage (see Figure 1), they already perceived CUREs to have a relative advantage over other teaching methods. Our analysis shows that this is largely true. Consistent with Andrews and Lemons (2015), who found that dissatisfaction with current methods was a prerequisite to making a change in teaching practices, dissatisfaction with old methods, and particularly dissatisfaction with cookbook-style labs, was a major motivator for using both PARE and other CUREs. In contrast to some previous studies of instructional change (e.g., Wilson, 2010; Henderson et al., 2011; Tagg, 2012), this specific population of instructors showed willingness, if not enthusiasm, for improving their students' laboratory experiences. Interviewed instructors expressed that increased student learning was a major advantage of using CUREs. This belief may reflect a growing consensus that CUREs have the potential to enhance student understanding of both biology content and the process of science (Brownell et al., 2012; Harris et al., 2015). Interestingly, increased student learning was a less prominent relative advantage theme for PARE specifically. All six of the instructors for whom the potential for increased student learning was a motivator for using PARE were instructors without prior CURE experience. This may reflect the current state of evidence-based teaching methods in their classes, naivete over how much potential a short-duration CURE such as PARE has for increased student learning, or PARE having different features that are more salient (and thus dominate the discussion) for CURE-experienced instructors than for inexperienced ones.

\section{Perceived Broader Impact Is Seen as a Major Relative Advantage of the PARE Project}

The PARE project research focuses on a topic that engages students in studying their local environments and prompts them to connect how scientific research can impact their own communities. Students serve as the primary collectors of data points for an ongoing national survey of potential antibiotic-resistant hot spots; answering the overarching research questions would not be possible without student participation. PARE's emphasis on studying a highly relevant question with ties to the students' local environments (broader impact) was the dominant relative advantage theme for these interviewed instructors. While relevance was also mentioned for CUREs in general, its prominence in discussions of PARE suggests that designing CUREs that connect to the local community and/or investigate a topic of broad, societal relevance could be a strong motivator for adoption.

\section{Compatibility with Course Structure and Content Was a Major Motivator for Using PARE}

The PARE project takes a modular approach to CURE design. The core module is short in duration and can be inserted into an existing course framework. Compatibility with course structure or content emerged as a major motivator for using PARE among the interviewed instructors and was frequently discussed alongside lamentations about lack of freedom to substantially change their laboratory courses to longer CURE experiences. Many instructors did not have complete control over their own courses and often had to maintain alignment with other sections or semesters of the same course or with associated lecture courses. As such, finding time in the semester in which to insert a CURE emerged as one of the most commonly discussed challenges for CUREs in general. In contrast, time in the semester was not a commonly cited challenge for instructors discussing the PARE project. While absence of evidence is not necessarily evidence of absence, this is consistent with the compatibility themes for PARE. Eight out of 11 instructors who cited time in the semester as a barrier for using CUREs also specifically mentioned compatibility with course structure as a motivating factor for using PARE.

The issue of using a short-duration CURE to overcome the barrier of time in the semester brings up a potentially difficult trade-off to consider for CURE design. On one hand, longer instructional time devoted to CUREs has been shown to result in more benefits for students, and thus students are likely to derive more positive gains from semester-long CUREs. However, for students whose instructors view the duration of these CUREs as a major barrier to their implementation, the result could be no CURE experience at all. It is our hope that PARE 
instructors for whom time in the semester is a barrier will eventually expand the length of their class research experiences by using additional PARE modules. There is some precedent that module-based CUREs can successfully translate to semester-long CURE experiences. For example, the Biochemistry Authentic Scientific Inquiry Lab CURE uses a flexible modular design and has successfully engaged instructors from a variety of course and institution types in using longer-length CURE experiences (Craig, 2017; Roberts et al., 2019). Further, Dahlberg et al. (2019) found that a short-duration CURE module enhanced complexity of student answers in problem-solving exercises and increased student self-efficacy and other positive outcomes usually associated with longer-length CUREs (Dahlberg et al., 2019). Many of the instructors in our study (as well as in Spell et al., 2014) express the need to emphasize laboratory skill building or to cover a very wide range of topics not compatible with a single semester-long CURE. For example, several instructors expressed that they did not think it possible to totally eliminate cookbook-style activities from laboratory courses and, therefore, were pleased that the PARE project would allow time in the semester for these activities. For some instructors, a short-duration CURE may be seen as a way to infuse some research design principles while also allowing time to cover multiple technical skills using traditional methods. Longitudinal studies are necessary to determine whether incorporation of a short CURE leads to expanded classroom research, how student outcomes change relative to the CURE duration, and whether short-duration modular CUREs can increase the rate of diffusion of CUREs.

\section{The Common CURE Barriers of Instructor Time and Cost May Be Alleviated with a Short-Duration CURE}

The PARE project is similar to other network CUREs in that it does not require instructors to spend time to develop protocols or research questions on their own. A lack of personal time or personal bandwidth to develop a CURE is one of the most commonly cited challenges to using CUREs (e.g., Lopatto et al., 2014; Spell et al., 2014; Shortlidge et al., 2016), and in our study, a lack of instructor bandwidth was the most commonly cited challenge to implementing CUREs. Our data suggest that a lack of instructor time/bandwidth is not a barrier for PARE. Of the 12 instructors who cited instructor bandwidth as a challenge or barrier to using CUREs, only one also had this concern for PARE. While there is some evidence that network CUREs may alleviate this common barrier (Lopatto et al., 2014), the creation of network CUREs alone is not sufficient to engage all potentially interested instructors. During the interviews, several instructors discussed their desire to use various network CUREs but were unable to do so, due to additional challenges, such as cost. Indeed, among the interviewed instructors, lack of available resources was tied with instructor bandwidth as the most commonly discussed CURE-related challenge theme, consistent with other studies (Spell et al., 2014; Shortlidge et al., 2016). Many instructors also expressed that their institutions did not have access to certain types of laboratory equipment or research resources (such as thermocyclers or sequencing centers). We found that compatibility with costs and resources was a motivator for using the PARE project, consistent with its low-cost design and lack of specialized equipment requirements (Genné-Bacon and Bascom-Slack, 2018). Simply put, instruc- tors were choosing to use PARE (in part) because they could afford it. Available resources were also seen as a barrier to using the PARE project; however, to a lesser extent than CUREs in general (six instructors citing as opposed to 11). The compatibility of PARE with instructor costs and resources complements the reported CURE complexity theme of available resources. Eight of the 11 instructors who mentioned PARE as cost compatible also mentioned available resources as a barrier for CUREs in general.

Interestingly, cost may be a particularly significant barrier for instructors with no previous CURE experience. Of the instructors who mentioned cost as a barrier to either PARE or other CUREs, the majority had never used a CURE before $(6 / 6$ for PARE, 9/12 for CUREs). This could indicate that the financial burden of CUREs is a primary deterrent for first-time CURE users. Without widespread systemic change in education funding, this issue is likely to persist. How CUREs can be designed to meet the needs of even the most resource-limited institutions should be a priority for future study.

\section{Student-Related Challenges Are an Ongoing Concern for All CURE Types}

An equal number of instructors touched on perceived student-related challenges for both PARE and CUREs. Subthemes of these challenges were student reluctance to engage with the CURE and a lack of student preparation or ability to carry out the CURE. This is consistent with our formative survey, which found that student ability was the largest concern among survey instructors before implementing PARE. Interestingly, though student challenge codes were (more or less) distributed across the three institution types when it comes to CUREs, the same was not true of these codes for PARE; none of the instructors mentioning student challenges for PARE were from doctorate-granting institutions. This is the only theme analyzed for which each institution type was not represented at least once. Though it is inappropriate to draw conclusions from such a small sample size, a possible explanation for this pattern is that PARE presents few challenges to instructors at research universities, but the perceived complexities remain a challenge for instructors at other types of colleges and universities.

\section{Limitations of This Study}

A caveat to this study is that interviews were conducted by a member of the PARE team, and instructors may not have felt as open about criticizing the PARE project as for other CUREs. Additionally, interviewees may have been more positive about the PARE project than they would have otherwise. Thus, while the data are useful to examine the positive motivators for using PARE discussed by instructors and the expressed challenges with other CUREs, they may not directly reflect the number of challenges expressed for CUREs versus PARE. As discussed previously, common complexity themes for CUREs (such as costs and resources and time in the semester) largely complement motivation for using PARE (such as compatibility with costs and resources and compatibility with course structure and content). It should also be noted that the main concerns about PARE largely correspond with those reported in the anonymous formative preimplementation survey of a different cohort of instructors. For example, student ability was the highest-ranking concern about PARE for both survey respondents 
and interviewed instructors. Additionally, survey respondents rated "making classroom time for this project" as not a challenge, which is consistent with how few instructors mentioned time in the semester as a challenge for PARE.

\section{Transferability of Results}

The most commonly reported barriers to using CUREs in the literature include time to develop a CURE (i.e., bandwidth), student preparation and resistance, financial or resource constraints, and large class size (Lopatto et al., 2014; Spell et al., 2014; Harris et al., 2015; Shortlidge et al., 2016). This study confirms several of these common barriers to using CUREs in general (time to develop/bandwidth, student preparation/ resistance, and costs/resources). In addition, we find time in the semester to be a significant barrier, which has also previously been reported by instructors currently or previously using the Genomics Education Partnership, a network CURE (Lopatto et al., 2014). Because our study and that of Lopatto et al. (2014) focus specifically on instructors considering or already implementing a network CURE, one explanation is that the time in the semester barrier is prominent for those considering or using network CUREs, but not for those who have already designed and taught their own CUREs. The lack of this theme in reference to PARE suggests that this perceived barrier may be relieved by a module-style CURE such as PARE.

The motivations and barriers for using PARE reported in this study differ somewhat from those previously reported in the literature for implementation of CUREs. While interviewed instructors anticipated facing some challenges with student preparation/resistance and cost/resources when using the PARE project, they largely did not report the common barriers of lack of bandwidth/time to develop or class size. The reason for these differences is not entirely clear. Previous literature has almost exclusively examined reported barriers postimplementation, and thus differences in barriers reported in this preimplementation study may reflect this different timepoint. However, given that many of our interviewed instructors had no previous CURE experience yet still recapitulated many of the same barriers to CURE use found in the literature, it may be more likely that differences are population specific or due to the programmatic differences of PARE (or network CUREs). The majority of previous literature on faculty barriers to CURE implementation has focused on faculty who developed their own CUREs (Spell et al., 2014; Shortlidge et al., 2016) or who were part of the development team of a network CURE (Craig, 2017). Thus, it is possible that instructors who are planning to adopt an established network CURE have different perceived barriers than those who have designed their own. There is some precedence for this: Shortlidge et al. (2017) found motivations for using CUREs differ between CURE developers and network CURE users. Similarly, a difference in complete alignment of the motivations reported in this study with the faculty motivations reported in Shortlidge et al.'s (2016) study of faculty perspectives on CUREs may again reflect a difference in type of CURE user (CURE designers vs. network CURE implementers) or a difference in the institutional context of surveyed instructors (fewer community colleges and PUIs). As CUREs continue to diffuse through the population and move from these early CURE adopters and innovators toward a wider population using a variety of different CURE types, studies on these mixed cohorts should provide clarity.
It is our hope that this type of study, in which the needs, motivations, and challenges of instructors planning to use a network CURE are examined in detail, will eventually lead to insight into how best to design CUREs so as to increase the rate of adoption by instructors and, therefore, to reach as many students as possible. Longitudinal studies with instructors using different network CURE programs from a diversity of institution types need to be conducted before broad generalizations can be made. However, some potential implications can be drawn from this study.

1. Short-duration CUREs may promote adoption by first-time users or instructors without complete autonomy over their courses. Among our interviewed instructors, the short duration of the PARE project was a major compatibility theme, while the length of other network CUREs was seen as a barrier.

2. Selecting research questions relevant to the lives of students may lead to more adoption of CUREs. We found that our interviewed instructors were highly motivated to use PARE because of its potential for societally relevant impact and connection to their local communities.

3. Designing CUREs with alignment to the student skill development goals for target laboratory courses may result in increased adoption. Some laboratory courses prioritize laboratory skill development, while others may prioritize scientific thinking. A CURE that is perceived as emphasizing scientific thinking over core skill development may be viewed as incompatible with a skills-based course by some instructors. Care should be taken to find a balance between these priorities when designing and promoting a network CURE. In addition, building CUREs that use techniques already taught in its target courses makes implementation easier for instructors.

4. The bandwidth/time to develop barrier to CURE use may be alleviated with short-duration network CUREs. Instructors in this study largely did not report a lack of bandwidth (i.e., instructor personal time and headspace) as a barrier to using the PARE project, despite reporting it as a barrier for other CUREs.

\section{Future Directions}

This study serves to examine the characteristics and decision-making process of a particular subpopulation of instructors who have expressed interest in implementing a particular CURE (the PARE project). While this is useful, we have not captured perceptions of the PARE project from instructors who may have considered PARE, but did not reach out to request information on it. Nevertheless, understanding why instructors choose to use the PARE project can provide insight for researchers and implementers interested in expanding participation in CUREs. Interestingly, approximately a year after initial interviews, 16 out of 19 of the interviewed instructors had proceeded to implement PARE in their courses (unpublished data). Future follow-up with this cohort of instructors will help to further clarify whether the preimplementation perceptions held by these instructors align with the actual experiences of implementation, and whether instructors continue to use PARE. Understanding these later stages of the decision process is important, because, in a study of research-based instructional strategies 
with physics faculty, the largest group to exit the decision process were those who had discontinued after trying (Henderson et al., 2012). Continued follow-up will also reveal whether instructors increase the length of the CURE experience in their classrooms (either through the use of PARE add-on modules or by transitioning to using another longer-length CURE). This could provide evidence for or against the use of short-duration CUREs as a viable entry point to CURE implementation and overall sustained CURE use. Similar longitudinal tracking of the decision-making process for instructors considering the use of different CUREs will help elucidate program-specific challenges, motivators, and the effects of each on sustained use.

\section{ACKNOWLEDGMENTS}

We thank all our contributing PARE instructors, particularly those who piloted interviews for us: Mike Buckholt, Lehman Ellis, Manuela Tripepi, Jennifer Larson, and Lubomira Cubonova. We thank all members of the Center for Translational Science Education at Tufts University for continuing support and insight. In particular we thank Berri Jacque, for his assistance in writing interview scripts and general support for our project, and Madeline Verbica, for illustrations. The National Science Foundation (DUE 1640399) provided the funding for this project. All human subjects protocols have been approved by the Tufts Institutional Review Board (protocol \#1511001) and comply with federal guidelines.

\section{REFERENCES}

Alexander, B. B., Foertsch, J., \& Daffinrud, S. (1998). The Spend a Summer with a Scientist Program: An evaluation of program outcomes and the essential elements for success. Madison, WI: University of MadisonWisconsin, LEAD Center.

Andrews, T. C., \& Lemons, P. P. (2015). It's personal: Biology instructors prioritize personal evidence over empirical evidence in teaching decisions. CBE-Life Sciences Education, 14(1), ar7.

Auchincloss, L. C., Laursen, S. L., Branchaw, J. L., Eagan, K., Graham, M., Hanauer, D. I., ... \& Dolan, E. L. (2014). Assessment of course-based undergraduate research experiences: A meeting report. CBE-Life Sciences Education, 13(1), 29-40.

Aud, S., Fox, M. A., \& KewalRamani, A. (2010). Status and trends in the education of racial and ethnic groups (NCES 2010-015). Washington, DC: U.S Department of Education, National Center for Education Statistics.

Austin, A. E. (2011). Promoting evidence-based change in undergraduate science education. Fourth Committee Meeting on Status, Contributions, and Future Directions of Discipline-Based Education Research held March 1, 2011, in Michigan State University, East Lansing, MI (pp. 1-25)

Bangera, G., \& Brownell, S. E. (2014). Course-based undergraduate research experiences can make scientific research more inclusive. CBE-Life Sciences Education, 13(4), 602-606.

Barral, A. M., Makhluf, H., Broderick, N. A., \& Kurt, E. L. (2016). The Small World Initiative ${ }^{T M}$ : An innovative crowdsourcing platform for antibiotics. FASEB Journal, 30(Suppl 1), 665.13-665.13. https://doi.org/10.1096/fasebj.30.1_ supplement.665.13

Beck, C., Butler, A., \& da Silva, K. B. (2014). Promoting inquiry-based teaching in laboratory courses: Are we meeting the grade? CBE-Life Sciences Education, 13(3), 444-452. https://doi.org/10.1187/cbe.13-12-0245

Blackburn, R. T., \& Lawrence, J. H. (1995). Faculty at work: Motivation, expectation, satisfaction. Baltimore, MD: Johns Hopkins University Press.

Brownell, S. E., \& Kloser, M. J. (2015). Toward a conceptual framework for measuring the effectiveness of course-based undergraduate research experiences in undergraduate biology. Studies in Higher Education, 40(3), 525-544. https://doi.org/10.1080/03075079.2015.1004234

Brownell, S. E., Kloser, M. J., Fukami, T., \& Shavelson, R. (2012). Undergraduate biology lab courses: Comparing the impact of traditionally based "cookbook" and authentic research-based courses on student lab experiences. Journal of College Science Teaching, 41(4)

Brownell, S. E., \& Tanner, K. D. (2012). Barriers to faculty pedagogical change: Lack of training, time, incentives, and ... tensions with professional identity? CBE-Life Sciences Education, 11(4), 339-346. Retrieved from http:// eutils.ncbi.nlm.nih.gov/entrez/eutils/elink.fcgi?dbfrom=pubmed\&id $=23222828$ \&retmode $=$ ref\& $\mathrm{cmd}=$ prlinks

Campbell, J. L., Quincy, C., Osserman, J., \& Pedersen, O. K. (2013). Coding in-depth semistructured interviews. Sociological Methods \& Research, 42(3), 294-320. Retrieved from http://journals.sagepub.com/doi/10.1177/ 0049124113500475

Carrese, J. (2015). CCURI regional conference and poster session. Bio-Link Next Generation National ATE Center for Biotechnology and Life Sciences,

Cartrette, D. P., \& Melroe-Lehrman, B. M. (2012). Describing changes in undergraduate students' preconceptions of research activities. Research in Science Education, 42, 1073-1100. https://doi.org/10.1007/s11165-011 $-9235-4$

Cohen, D., \& Crabtree, B. (2006). Semi-structured interviews. Qualitative Research Guidelines Project. Retrieved April 17, 2020, from www.qualres org/HomeSemi-3629.html

Community College Undergraduate Research Initiative and Council on Undergraduate Research. (2015). Investing in impact: The power of undergraduate research, community college perspectives. Retrieved November 11, 2018, from www.cur.org

Cooper, K. M., Blattman, J. N., Hendrix, T., \& Brownell, S. E. (2019). The impact of broadly relevant novel discoveries on student project ownership in a traditional lab course turned CURE. CBE-Life Sciences Education, 18(4), ar57. https://doi.org/10.1187/cbe.19-06-0113

Cooper, K. M., Soneral, P. A. G., \& Brownell, S. E. (2017). Define your goals before you design a CURE: A call to use backward design in planning course-based undergraduate research experiences. Journal of Microbiology \& Biology Education, 18(2). https://doi.org/10.1128/jmbe .v18i2.1287

Corwin, L. A., Runyon, C. R., Ghanem, E., Sandy, M., Clark, G., Palmer, G. C., ... \& Dolan, E. L. (2018). Effects of discovery, iteration, and collaboration in laboratory courses on undergraduates' research career intentions fully mediated by student ownership. CBE-Life Sciences Education, 17(2) ar20. https://doi.org/10.1187/cbe.17-07-0141

Corwin, L. A., Runyon, C., Robinson, A., \& Dolan, E. L. (2015). The Laboratory Course Assessment Survey: A tool to measure three dimensions of research-course design. CBE-Life Sciences Education, 14(4), ar37. https:// doi.org/10.1187/cbe.15-03-0073

Craig, P. A. (2017). A survey on faculty perspectives on the transition to a biochemistry course-based undergraduate research experience laboratory. Biochemistry and Molecular Biology Education, 45(5), 426-436. Retrieved from http://doi.wiley.com/10.1002/bmb.21060

Dahlberg, C., Lee, S., Leaf, D., Lily, L., Wiggins, B., Jordt, H., \& Johnson, T. (2019). A short, course-based research module provides metacognitive benefits in the form of more sophisticated problem solving. Journal of College Science Teaching, 48(4), 22-30. https://doi.org/10.2505/4/ jcst19_048_04_22

Dearing, J. W. (2009). Applying diffusion of innovation theory to intervention development. Research on Social Work Practice, 19(5) 503-518. Retrieved from http://journals.sagepub.com/doi/10.1177/ 1049731509335569

Dolan, E. (2016). Course-based undergraduate research experiences: Current knowledge and future directions. Retrieved November 11, 2018, from https://sites.nationalacademies.org/cs/groups/dbassesite/documents/ webpage/dbasse_177288.pdf

Ertmer, P. A. (1999). Addressing first- and second-order barriers to change: Strategies for technology integration. Educational Technology Research and Development, 47, 47-61. https://doi.org/10.1007/BF02299597

Fuller, F. F. (1969). Concerns of teachers: A developmental conceptualization. American Educational Research Journal, 6(2), 207-226. https://doi org/10.3102/00028312006002207

Genné-Bacon, E. A., \& Bascom-Slack, C. A. (2018). The PARE project: A short course-based research project for national surveillance of antibiotic-resistant microbes in environmental samples. Journal of Microbiology \& Biology Education, 19(3). Retrieved from www.asmscience.org/content/ journal/jmbe/10.1128/jmbe.v19i3.1603 
Goedhart, C. M., \& McLaughlin, J. S. (2015). Overcoming the barrier to implementing authentic research experiences through faculty mentorship. CBE-Life Sciences Education, 14(2), le1.

Goodwin, E., Cao, J., Fletcher, M., Flaiban, J., \& Shortlidge, E. (2018). Catching the wave: Are biology graduate students on board with evidence-based teaching? CBE-Life Sciences Education, 17(3), ar43. https://doi.org/10.1187/cbe.17-12-0281

Graham, M. J., Frederick, J., Byars-Winston, A., Hunter, A.-B., \& Handelsman, J. (2013). Science education. Increasing persistence of college students in STEM. Science, 341(6153), 1455-1456.

Hall, G. E. (1979). The concerns-based approach to facilitating change. Educational Horizons, 57(4), 202-208.

Hanauer, D. I., \& Dolan, E. L. (2014). The Project Ownership Survey: Measuring differences in scientific inquiry experiences. CBE-Life Sciences Education, 13(1), 149-158. https://doi.org/10.1187/cbe.13-06-0123

Hanauer, D. I., Frederick, J., Fotinakes, B., \& Strobel, S. A. (2012). Linguistic analysis of project ownership for undergraduate research experiences. CBE-Life Sciences Education, 11(4), 378-385. https://doi.org/10.1187/ cbe.12-04-0043

Harris, A., Babkoor, M., Gu, T., \& Kremer, G. E. (2015). Course-based undergraduate research: A review of models $\&$ practices. Paper presented at: ASME 2015 International Design Engineering Technical Conferences and Computers and Information in Engineering Conference 2015, Boston (pp. 1-10). Retrieved April. 17, 2020, from http://publication/uuid/ 305A1A48-0166-46AB-BA2D-9CA5A2C99CC9

Harrison, M., Dunbar, D., Ratmansky, L., Boyd, K., \& Lopatto, D. (2011). Classroom-based science research at the introductory level: Changes in career choices and attitude. CBE-Life Sciences Education, 10(3), 279286.

Hatfull, G. F., Pedulla, M. L., Jacobs-Sera, D., Cichon, P. M., Foley, A., Ford, M. E., ... \& Hendrix, R. W. (2006). Exploring the mycobacteriophage metaproteome: Phage genomics as an educational platform. PLoS Genetics, 2(6), e92. https://doi.org/10.1371/journal.pgen.0020092

Heim, A. B., \& Holt, E. A. (2019). Benefits and challenges of instructing introductory biology course-based undergraduate research experiences (CUREs) as perceived by graduate teaching assistants. CBE-Life Sciences Education, 18(3), ar43. https://doi.org/10.1187/cbe.18-09-0193

Henderson, C., Beach, A., \& Finkelstein, N. (2011). Facilitating change in undergraduate STEM instructional practices: An analytic review of the literature. Journal of Research in Science Teaching, 48(8), 952-984. https:// doi.org/10.1002/tea.20439

Henderson, C., \& Dancy, M. (2007). Barriers to the use of research-based instructional strategies: The influence of both individual and situational characteristics. Physical Review Special Topics-Physics Education Research, 3(2), 20102. https://doi.org/10.1103/PhysRevSTPER.3.020102

Henderson, C., \& Dancy, M. H. (2008). Physics faculty and educational researchers: Divergent expectations as barriers to the diffusion of innovations. American Journal of Physics, 76(1), 79-91. http://aapt.scitation.org/ doi/10.1119/1.2800352

Henderson, C., Dancy, M., \& Niewiadomska-Bugaj, M. (2012). Use of research-based instructional strategies in introductory physics: Where do faculty leave the innovation-decision process? Physical Review Special Topics-Physics Education Research, 8(2), 101.

Howard, D. R., \& Miskowski, J. A. (2005). Using a module-based laboratory to incorporate inquiry into a large cell biology course. Cell Biology Education, 4(3), 249-260. https://doi.org/10.1187/cbe.04-09-0052

Jordan, T. C., Burnett, S. H., Carson, S., Caruso, S. M., Clase, K., DeJong, R. J., ... \& Hatfull, G. F. (2014). A broadly implementable research course in phage discovery and genomics for first-year undergraduate students. MBio, 5(1), e01051-13. https://doi.org/10.1128/mBio.01051-13

Kremer, J. F., \& Bringle, R. G. (1990). The effects of an intensive research experience on the careers of talented undergraduates. Journal of Research \& Development in Education, 24(1), 1-5.

Kuh, G. D. (2008). Excerpt from high-impact educational practices: What they are, who has access to them, and why they matter. Association of American Colleges and Universities, 14(3), 28-29.

Laursen, S., Hunter, A.-B., Seymour, E., Thiry, H., \& Melton, G. (2010). Undergraduate research in the sciences: Engaging students in real science. San Francisco, CA: Jossey-Bass.
Linn, M. C., Palmer, E., Baranger, A., Gerard, E., \& Stone, E. (2015). Undergraduate research experiences: Impacts and opportunities. Science, 347(6222), 1261757. www.sciencemag.org/cgi/doi/10.1126/science.1261757

Lopatto, D. (2004). Survey of Undergraduate Research Experiences (SURE): First findings. Cell Biology Education, 3(4), 270-277. https://doi .org/10.1187/cbe.04-07-0045

Lopatto, D., Alvarez, C., Barnard, D., Chandrasekaran, C., Chung, H. M., Du, C., ... \& Elgin, S. C. R. (2008). Genomics Education Partnership. Science, 322(5902), 684-685. https://doi.org/10.1126/science.1165351

Lopatto, D., Hauser, C., Jones, C. J., Paetkau, D., Chandrasekaran, V., Dunbar, D., ... \& Elgin, S. C. R. (2014). A central support system can facilitate implementation and sustainability of a classroom-based undergraduate research experience (CURE) in genomics. CBE-Life Sciences Education, 13(4), 711-723.

Lund, T. J., \& Stains, M. (2015). The importance of context: An exploration of factors influencing the adoption of student-centered teaching among chemistry, biology, and physics faculty. International Journal of STEM Education, 2(1), 13.

Mathur, V., Arora, G. S., McWilliams, M., Russell, J., \& Rosenwald, A. G. (2019). The Genome Solver Project: Faculty training and student performance gains in bioinformatics. Journal of Microbiology \& Biology Education, 20(1). Retrieved from www.asmscience.org/content/journal/jmbe/ 10.1128/jmbe.v20i1.1607

Mullin, C. M. (2011). The road ahead: A look at trends in the educational attainment of community college students (AACC Policy Brief 2011-04PBL). Washington, DC: American Association of Community Colleges.

Nagda, B. A., Gregerman, S. R., Jonides, J., Von Hippel, W., \& Lerner, J. S. (1998). Undergraduate student-faculty research partnerships affect student retention. Review of Higher Education, 22(1), 55-72.

National Academies of Sciences Engineering and Medicine. (2015). Integrating discovery-based research into the undergraduate curriculum. Washington, DC: National Academies Press. https://doi.org/10.17226/21851

National Research Council. (2012). Discipline-based education research: Understanding and improving learning in undergraduate science and engineering. Washington, DC: National Academies Press.

President's Council of Advisors on Science and Technology. (2012). Engage to excel: Producing one million additional college graduates with degrees in science, technology, engineering, and mathematics. Report to the president. Washington, DC: U.S. Government Office of Science and Technology. Retrieved September 14, 2014, from https://obamawhitehouse .archives.gov/sites/default/files/microsites/ostp/pcast-engage-to-excel -final_2-25-12.pdf

Parker, L. C., Adedokun, O., \& Weaver, G. C. (2015). Culture, policy and resources: Barriers reported by faculty implementing course reforms. In Transforming institutions: Undergraduate STEM education for the 21st century (pp. 125-139). West Lafayette: Purdue University Press.

Pundak, D., \& Rozner, S. (2008). Empowering engineering college staff to adopt active learning methods. Journal of Science Education and Technology, 17, 152-163. http://link.springer.com/article/10.1007/s10956 -007-9057-3

Roberts, R., Hall, B., Daubner, C., Goodman, A., Pikaart, M., Sikora, A., \& Craig, P. (2019). Flexible Implementation of the BASIL CURE. Biochemistry and Molecular Biology Education, 47(5), 498-505. https://doi.org/10.1002/bmb.21287

Rodenbusch, S. E., Hernandez, P. R., Simmons, S. L., \& Dolan, E. L. (2016). Early engagement in course-based research increases graduation rates and completion of science, engineering, and mathematics degrees. CBE-Life Sciences Education, 15(2), ar20.

Rogers, E. M. (1962). Diffusion of innovations (1st ed.). New York: Free Press of Glencoe.

Rogers, E. M. (2004). Diffusion of innovations (3rd ed.). New York: Free Press of Glencoe.

Russell, C. B., \& Weaver, G. C. (2011). A comparative study of traditional, inquiry-based, and research-based laboratory curricula: Impacts on understanding of the nature of science. Chemistry Education Research and Practice, 12, 57-67. https://doi.org/10.1039/c1rp90008k

Russell, S. H., Hancock, M. P., McCullough, J., Roessner, J. D., Storey, C., ... \& Elgin, C. (2005). Evaluation of NSF support for undergraduate research opportunities: survey of STEM graduates: draft final report. Menlo Park, CA: SRI International. 
Shadle, S. E., Marker, A., \& Earl, B. (2017). Faculty drivers and barriers: Laying the groundwork for undergraduate STEM education reform in academic departments. https://doi.org/10.1186/s40594-017-0062-7

Shaffer, C. D., Alvarez, C., Bailey, C., Barnard, D., Bhalla, S., Chandrasekaran C., ... \& Elgin, S. C. R. (2010). The Genomics Education Partnership: Successful integration of research into laboratory classes at a diverse group of undergraduate institutions. CBE-Life Sciences Education, 9(1), 55-69. https://doi.org/10.1187/09-11-0087

Shortlidge, E., Bangera, G., \& Brownell, S. (2016). Faculty perspectives on developing and teaching course-based undergraduate research experiences. BioScience, 66(1), 54-62. https://doi.org/10.1093/biosci/biv167

Shortlidge, E., Bangera, G., \& Brownell, S. (2017). Each to Their Own CURE: Faculty Who Teach Course-Based Undergraduate Research Experiences Report Why You Too Should Teach a CURE. Journal of Microbiology $\&$ Biology Education, 18(2).

Spell, R. M., Guinan, J. A., Miller, K. R., \& Beck, C. W. (2014). Redefining authentic research experiences in introductory biology laboratories and barriers to their implementation. CBE-Life Sciences Education, 13(1), 102-110.

Tagg, J. (2012). Why does the faculty resist change? Change: The Magazine of Higher Learning, 44(1), 6-15.

Tiny Earth. (n.d.). Home page. Retrieved January 13, 2020, from https:// tinyearth.wisc.edu

Walczyk, J. J., Ramsey, L. L., \& Zha, P. (2007). Obstacles to instructional innovation according to college science and mathematics faculty. Journal of Research in Science Teaching, 44(1), 85-106. https://doi.org/10.1002/tea.20119

Warford, M. K. (2010). Testing a diffusion of innovations in education model. The Innovation Journal: The Public Sector Innovation Journal, 10(3).

Wilson, R. (2010). Why teaching is not priority no. 1. Chronicle of Higher Education, 57(3), A1-A8.

Zydney, A. L., Bennett, J. S., Shahid, A., \& Bauer, K. W. (2002). Impact of undergraduate research experience in engineering. Journal of Engineering Education, 91(2), 151-157. https://doi.org/10.1002/j.2168-9830.2002 .tb00687.x 